\title{
Do Racial Disparities Exist during Pretrial Decisionmaking? Evidence from North Carolina
}

\author{
Guangya Liu, Chloe Johnson and Neil Vidmar*
}

\section{INTRODUCTION}

Racial Disparities in the Criminal Justice System are well documented in that minority defendants are over- represented compared with white defendants. The factors that account for the racial disparities are complex and include different levels of criminal activity, law enforcement resources, legislative policies, and decision making by various actors including policymakers, judges, attorneys and other practitioners at various stages of the justice process. However, our understanding of racial disparities during pretrial proceedings is quite limited. The present authors argue that it is crucial to study the pretrial stages because they are a pivotal point in the criminal justice process continuum and racial disparities may begin to take root at an early stage of the process.

Several national studies suggest that minority defendants are more likely to be held in jail prior to adjudication, that they are assigned higher bail amounts than whites, and that they are more likely than whites to receive more severe bail options. Furthermore, pretrial detention has a number of “spillover” effects on later outcomes for defendants. For example, defendants detained before trial plead guilty more often, are convicted at a higher rate, and are sentenced to jail or prison more often than those who are released early in the process. Finally, pretrial release involves decisions and arguments made by many criminal justice stakeholders-law 
enforcement, Magistrates, Judges, defense attorneys, district attorneys, and, where available, pretrial services.

\section{METHODOLOGY}

We analyze data from 102 randomly selected defendants in Halifax County, a rural county in the First Judicial Division, District 6A in the northeastern part of North Carolina. Our samples were chosen randomly from a list of Class $\mathrm{H}$ felony cases provided by the Administrative Office of the Courts under the following criteria: 1) cases from districts 6B and 18, 2) with a Class $\mathrm{H}$ felony as the top, initiating charge, 3) cases that have been closed (unless this was not an easy parameter to include, then the technician would substitute cases that were initiated at least 9 months prior, 4) cases that were initiated no earlier than 1/1/10. We decided to avoid cases that were more than three or four years old because older cases would raise questions about comparability, due to changes in policies, procedures, and law.

We conducted $t$-tests for continuous variables and chi square tests for categorical variables to compare differences between whites and minorities. We also conducted regression analysis and evaluated the effects of race on bond amount and outcomes, after controlling for covariates.

\section{RESULTS}

\section{Types of Bonds}

There are five types of bonds that can be given to any defendant: custody, cash, secured, unsecured, and written promise to appear. Among 99 defendants, one defendant received a cash bond, two received a custody bond, 75 received a secured bond, and 21, an unsecured bond. In 
our sample, no written promises to appear were given. Thus, $76 \%$ of the time defendants were receiving secured bonds, $21 \%$ of the time they were receiving unsecured bonds, and $2 \%$ or less of the time they received cash or custody bonds.

Our initial analysis only broke down the type of bond assigned by race through documenting how the bond was actually posted. When we look at the methods of posting bond, we see that the cash bond was given to a black individual, the custody bonds were once for a black defendant and the other time for a white defendant. Black defendants were given unsecured bonds $27 \%$ of the time and secured bonds $68 \%$ of the time. White defendants were given unsecured bonds $33 \%$ of the time, and secured bonds $63 \%$ of the time.

\section{Amount of Bond Set}

The population for the regression model that would determine how to describe the relationship between race and bond amount was 62 black defendants and 39 white defendants, for a total of 101 defendants. The mean bond for Halifax County based on our sample was $\$ 18,040$. If we remove the Magistrates for whom we only have one or two examples of bonds set, we see that the mean bond amount given ranged from a low of $\$ 3,750$ to a high of $\$ 26,571$. The overall mean bond for the black defendants was $\$ 19,710$ and the mean bond for white defendants was $\$ 15,385$. Therefore, there was a difference in the amounts of bonds set based on race, in that the mean bond for blacks was $\$ 4,325$ higher than that set for white defendants.

Control variables for the following factors in the regression analysis were: criminal histories, previous failures to appear in court, age, gender, the number of associated cases, and the number of offenses for which bond was being set. We found that race was not a significant factor in the amounts of bonds set.

\section{Ability to Post Bond}


We found that $26 \%$ of the black defendants were not able to post bond, as compared to $28 \%$ of white defendants. Black defendants who were also unable to post bond (16/100) spent a mean of 303 days in jail, compared to white defendants who were unable to post bond (10/100) spending a mean a 125 days in jail.

\section{CONCLUSION}

We find some evidence of racial disparities in pretrial decisionmaking. The type of bond assigned differs by race. Black defendants who were unable to post bond (16/100) spent a mean of 303 days in jail, compared to white defendants who were unable to post bond (10/100) spending a mean a 125 days in jail. However, race is not a significant predictor of bond amount in the regression analysis, indicating that racial disparities may not be as pronounced as some advocates believe in terms of bond amounts set by judges. However, we acknowledge that the findings are limited due to small sample size and cautions should be taken when generalizing the findings. The completed research will have a much larger sample.

Guangya Liu and Neil Vidmar are at Duke Law School; Chloe Johnson is a lawyer with North Carolina Advocates for Justice 